\title{
Editorial: Progress in Episodic Memory Research
}

\author{
Ekrem Dere ${ }^{1,2 *}$, Armin Zlomuzica ${ }^{3}$, Angelica Staniloiu ${ }^{4,5,6}$ and Hans J. Markowitsch ${ }^{4}$ \\ ${ }^{1}$ Teaching and Research Unit Life Sciences, University Pierre and Marie Curie, Paris, France, ${ }^{2}$ Max Planck Institute of \\ Experimental Medicine, Göttingen, Germany, ${ }^{3}$ Mental Health Research and Treatment Center, Ruhr-University Bochum, \\ Bochum, Germany, ${ }^{4}$ Department of Physiological Psychology, University of Bielefeld, Bielefeld, Germany, ${ }^{5}$ Sunnybrook \\ Health Science Center, Toronto, ON, Canada, ${ }^{6}$ Department of Psychiatry, University of Toronto, Toronto, ON, Canada
}

Keywords: episodic memory, episodic-like memory, episodic future thinking, mental time travel, animal feed

\section{The Editorial on the research topic}

\section{Editorial: Progress in Episodic Memory Research}

Episodic memory refers to the ability to mentally time travel into the past and to remember personal experiences in terms of what happened and where and when it happened and to be autonoetically aware of it (Tulving, 2002). Humans (and perhaps also animals) are able to remember the specific perceptions, emotions and thoughts they had during a particular experience. This highly sophisticated and unique memory system is extremely sensitive to cerebral aging, neurodegenerative and neuropsychiatric diseases.

Episodic memory, as the sum of our experiences, is the supporting pillar of our identity and reminds us about our preferences and aversions, our strengths and weaknesses and helps us to anticipate how we will think, feel and behave in the future. Therefore, episodic memories are extremely useful for solving problems in the present and to plan for the future (Breeden et al., 2016).

OPEN ACCESS

Edited and reviewed by: Nuno Sousa, University of Minho, Portugal

*Correspondence: Ekrem Dere dere@em.mpg.de ekrem.dere@upmc.fr

Received: 17 February 2016 Accepted: 14 March 2016 Published: 30 March 2016

Citation:

Dere E, Zlomuzica A, Staniloiu A and Markowitsch HJ (2016) Editorial:

Progress in Episodic Memory Research.

Front. Behav. Neurosci. 10:61. doi: 10.3389/fnbeh.2016.00061
The field of episodic memory research is a continuously expanding and fascinating area that unites a broad spectrum of scientists who represent a variety of research disciplines including neuroscience, behavioral genetics, medicine, neuropharmacology, psychology and philosophy. Nevertheless, important questions still remain to be addressed.

This research topic on the Progress in Episodic Memory Research covers past, current and future directions in research dedicated to the neurobiology, neuropathology, development, measurement and rehabilitation of episodic memory. A total of 171 high-rank international scientists have contributed to a compilation of 43 articles.

Among these 43 articles the reader will find (already well cited) original research (Alston et al.; Bai et al.; Barbosa et al.; Baumann et al.; Chen et al.; Coman et al.; Dalton et al.; Denkova et al.; Denkova et al.; Guillery-Girard et al.; Habermas and Diel; Henke et al.; Kanatsou et al.; Kinugawa et al.; Meyer et al.; Mulder et al.; Rauchs et al.; Reber et al.; Risius et al.; Shafer and Dolcos; Sperduti et al.; Staniloiu et al.; Todd et al.; Xiu et al.), opinion (Szpunar et al.) and review articles (Brod et al.; Friedman; Griffin and Hallock; Irish and Piguet; Mizumori; Muller; Murray and Kensinger; Pause et al.; Pergola and Suchan; Schnider; Souchay et al.; Werner et al.; Zlomuzica et al.), as well as hypothesis and theory papers (Dalla Barba and La Corte; Klein; Urbanowitsch et al.; Vandekerckhove et al.; Yassa and Reagh) from both human and animal research disciplines. 
With this Frontiers eBook, we (the editors) aimed to cover the full diversity of methods and theoretical approaches to unravel this veritable "marvel of nature" (Tulving, 2002) that we call episodic memory.

\section{REFERENCES}

Breeden, P., Dere, D., Zlomuzica, A., and Dere, E. (2016). The mental time travel continuum: on the architecture, capacity, versatility and extension of the mental bridge into the past and future. Rev. Neurosci. doi: 10.1515/revneuro-20150053. [Epub ahead of print].

Tulving, E. (2002). Episodic memory: from mind to brain. Annu. Rev. Psychol. 53, 1-25. doi: 10.1146/annurev.psych.53.100901.135114

Conflict of Interest Statement: The authors declare that the research was conducted in the absence of any commercial or financial

\section{AUTHOR CONTRIBUTIONS}

All authors listed, have made substantial, direct and intellectual contribution to the work, and approved it for publication.

relationships that could be construed as a potential conflict of interest.

Copyright (C) 2016 Dere, Zlomuzica, Staniloiu and Markowitsch. This is an openaccess article distributed under the terms of the Creative Commons Attribution License (CC BY). The use, distribution or reproduction in other forums is permitted, provided the original author(s) or licensor are credited and that the original publication in this journal is cited, in accordance with accepted academic practice. No use, distribution or reproduction is permitted which does not comply with these terms. 